\title{
Caracterização geológica da porção centro-sul da Bacia Pernambuco com base na integração de modelo digital de elevação, dados magnetométricos e geológicos
}

\author{
Vivian Silvani de Arruda PASSOS, Mário Ferreira de LIMA FILHO, Thais Andressa \\ CARRINO \& Flávia Azevedo PEDROSA
}

Departamento de Geologia, Centro de Tecnologia e Geociências, Universidade Federal de Pernambuco. Av. da Arquitetura s/n, CEP 50740-550, Recife, PE, Brasil (vivian.silvani@hotmail.com, mflf@ufpe.br, thais.carrino@gmail.com, flaviapedrosa.geo@gmail.com).

Resumo. Este trabalho descreve os principais aspectos geológicos, em escala de detalhe, observados para a porção centro-sul da Bacia Pernambuco, localizada em parte dos municípios de Ipojuca e Sirinhaém (PE). Seis unidades litoestratigráficas puderam ser individualizadas: o embasamento cristalino (rochas metamórficas intemperizadas), a Formação Cabo (conglomerados polimíticos), a Suíte Magmática Ipojuca (riolitos, basaltos e rochas piroclásticas), as formações Estiva (folhelhos verdes, calcíferos, com ausência de microfósseis) e Algodoais (argilitos e arenitos médios a finos, com fácies sedimentar vulcanogênica associada), e depósitos quaternários. Foram utilizadas ferramentas como o modelo digital de elevação (MDE) da Triangulated Irregular Network (TIN), derivado dos dados topográficos da Folha Sirinhaém (escala 1:25.000) e o mapa de amplitude do sinal analítico para auxiliar a cartografia geológica. Os lineamentos topográficos e magnéticos (trends NNW-ESE, NW-SE e NE-SW) correspondem à fase rifte. Esses lineamentos estão relacionados a falhas de borda (evento inicial) e, principalmente, à reativação dessas falhas, combinada à geração de novas falhas. Vinte e seis anomalias magnéticas positivas e circulares foram identificadas e podem refletir a assinatura de possíveis centros vulcânicos. Atentamos a ocorrência de dois possíveis grandes centros vulcânicos que se propagam em direção ao Platô de Pernambuco, sendo que um está localizado na porção leste da área (CV1), onde ocorre o maior volume de sedimentação quaternária, e o outro está inserido na porção sudoeste (CV2), e excede os limites da área estudada.

Palavras-chave. bacia marginal, integração de dados, centros vulcânicos, Suíte Magmática Ipojuca.

\begin{abstract}
GEOLOGICAL CHARACTERIZATION OF THE SOUTH-CENTRAL PORTION OF THE PERNAMBUCO BASIN BASED ON THE INTEGRATION OF DIGITAL ELEVATION MODEL, MAGNETIC AND GEOLOGICAL DATA. This paper describes the main geological aspects, on a detailed scale, observed at the south-central portion of the Pernambuco Basin, located in a part of the Ipojuca and Sirinhaém municipalities (PE). Six lithostratigraphic units were individualized: the crystalline basement (weathered metamorphic rocks), the Cabo Formation (polymictic conglomerates), the Ipojuca Magmatic Suite (rhyolites, basalts, and pyroclastic rocks), the Estiva (green shale with the absence of microfossils), and Algodoais formations (claystones and medium- to fine-grained sandstones, associated with a volcanogenic sedimentary facies), and quaternary deposits. Triangulated Irregular Network (TIN) digital elevation model (DEM) derived from the Sirinhaém Topographic Sheet (1:25,000 scale), and the analytic signal amplitude map were used to aid the geological cartography. The topographic and magnetic lineaments (trends NNW-ESE, NW-SE and NE-SW) correspond to the rift phase. These lineaments are related to edge faults (initial event) and, mainly, their reactivations, combined with new faults. Twenty-six circular magnetic anomalies have been identified and may reflect the signature of possible volcanic centers. We note the occurrence of two possible large volcanic centers that propagate towards the Pernambuco Plateau; one center is located in the eastern portion (CV1), where the largest volume of quaternary sedimentation occurs, and the other center (CV2) is located in the southwestern portion, at the border of the studied area.
\end{abstract}

Keywords. marginal basin, data integration, volcanic centers, Ipojuca Magmatic Suite. 


\section{Introdução}

Localizada no Nordeste do Brasil, a Bacia Pernambuco é uma bacia marginal atlântica, do tipo rifte, abrangendo uma faixa com $900 \mathrm{~km}^{2}$. Está posicionada entre a Zona de Cisalhamento Pernambuco Leste, seu limite ao norte, o Alto de Maragogi-Barreiros, seu limite sul, e o Domínio Pernambuco-Alagoas, a oeste (Lima Filho, 1998; Fig. 1A).

A Bacia Pernambuco pode ser dividida em duas sub-bacias delimitadas pelo Alto Estrutural de Maracatu (Fig. 1A): i) a Sub-bacia Norte, entre a Zona de Cisalhamento Pernambuco Leste e o Alto Estrutural do Cabo de Santo Agostinho, e ii) a Sub-bacia Sul, delimitada pelos Altos Estruturais do Cabo de Santo Agostinho e de MaragogiBarreiros (Lima Filho, 1998; Maia, 2012; Correia Filho, 2017). Pode ainda ser dividida na porção onshore, ocupando uma estreita faixa ao longo do litoral oriental nordestino (Rifte do Cupe), e na porção offshore, localizada em águas profundas e ultraprofundas (Platô de Pernambuco) (Lima Filho et al., 2006; Maia, 2012).

O presente estudo aborda a caracterização geológica de superfície, em escala 1:25.000, de uma área com aproximadamente 100 $\mathrm{km}^{2}$, localizada na porção centro-sul da Bacia Pernambuco, abrangendo parte dos municípios de Ipojuca e Sirinhaém (PE) (Fig. 1B). Especificamente, a área estudada está inserida entre as praias de Maracaipe e Ponta de Serrambi. O estudo tem o intuito de compreender as relações estratigráficas, principalmente, entre as unidades sedimentares e vulcânicas que ocorrem nessa porção da Bacia Pernambuco, a partir da análise integrada de dados geológicos, geomorfológicos e magnéticos.

\section{Contexto geológico}

A seguir, são descritas as unidades litoestratigráficas encontradas na região centrosul da Bacia Pernambuco. Destaca-se que, no contexto da estratigrafia da bacia, foram utilizados dois trabalhos como referências relevantes, que sugerem ideias complementares, a saber: Córdoba et al. (2007), que propuseram a carta estratigráfica das bacias Pernambuco e
Paraíba, publicada pela Petrobrás, além de Lima Filho (1998), com reconsiderações sobre a carta estratigráfica para Bacia Pernambuco.

\subsection{Embasamento cristalino}

O embasamento cristalino aflorante da Bacia Pernambuco é representado por rochas supracrustais do Domínio Pernambuco-Alagoas (PEAL) e pelo Batólito Ipojuca-Atalaia, Província Borborema. O Domínio PEAL é constituído por gnaisses, migmatitos e granitos que atuaram como um grande bloco estrutural durante a deformação brasiliana (Silva Filho et al., 2002; Van Schmus et al., 2011).

O Domínio PEAL integra complexos basais paleoproterozoicos (Neves et al., 2005; Osako, 2005; Silva Filho et al., 2016), três sequências supracrustais proterozoicas, e batólitos graníticos neoproterozoicos (Silva Filho et al., 2002, 2014, 2016). Com base em dados petrográficos, Silva Filho et al. (2002) agrupam o Batólito Ipojuca-Atalaia, de idade modelo Sm-Nd $T_{\text {DM }}$ variando de 1,92 a 2,43 $\mathrm{Ga}$, em dois grupos de granitoides: i) álcali-feldspato granito à duas micas e sienogranito, e ii) anfibólio monzogranito a quartzo sienito.

\subsection{Formação Cabo}

A Formação Cabo corresponde à unidade basal da Bacia Pernambuco, composta por sistemas de leques aluviais e lacustres depositados em contexto tectonicamente ativo, cuja deposição sin-rifte já estaria em curso há cerca de 115,0 Ma (Mesoaptiano) (Córdoba et al., 2007).

Lima Filho (1998) divide a Formação Cabo em três fácies: proximal, mediana e distal. Córdoba et al. (2007) tratam as divisões das fácies da Formação Cabo propostas por Lima Filho (1998) apenas como Formação Cabo, não individualizando a deposição cíclica desenvolvida pelas alternâncias entre águas lacustres profundas e rasas e, a esta formação, incluem uma seção evaporítica de provável idade Neoaptiana/Eoalbiana. Maia (2012) e Maia et al. (2012) mencionam a presença, no topo da Formação Cabo, de depósitos evaporíticos e 


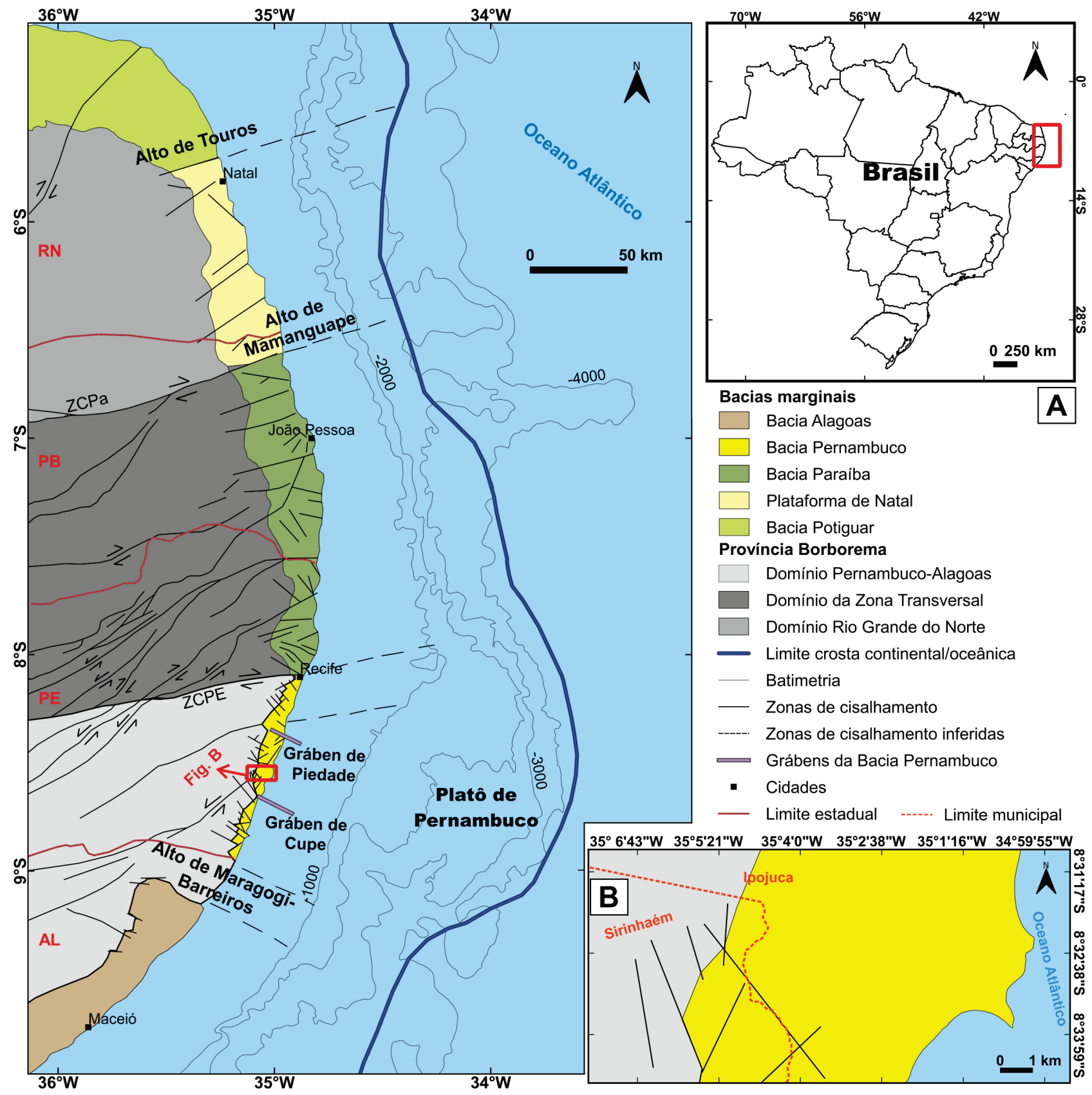

Figura 1. Mapas de localização. A) Mapa geológico regional de bacias marginais do Nordeste oriental do Brasil, controladas por zonas de cisalhamento e por altos regionais, e indicação do limite de crosta continental-oceânica (Magalhães et al., 2014); B) Detalhe da área de estudo (vide Fig. 1A, indicada pelo polígono vermelho). Zonas de cisalhamento: ZCPa, Patos; ZCPE, Pernambuco Leste. Modificado de Barbosa et al. (2008) e Maia (2012).

Figure 1. Localization maps. A) Geological regional map of marginal basins from the eastern coast of Northeast of Brazil, controlled by shear zones and regional highs, an indication of the continental-oceanic crust limit (Magalhães et al., 2014); B) Detail of the studied area (see Fig. 1A, indicated by the red polygon). Shear zones: ZCPa, Patos; ZCPE, East Pernambuco. Modified from Barbosa et al. (2008) and Maia (2012). 
conglomeráticos com cimentação carbonática, sugerindo que estes estariam relacionados a um ambiente mais árido, onde se formaram sabkhas continentais na região distal das planícies aluviais.

\subsection{Suíte Magmática Ipojuca}

Segundo Nascimento (2003), a Bacia Pernambuco exibe uma ampla variação de rochas ígneas datadas em cerca de 102,0 Ma pelo método ${ }^{40} \mathrm{Ar} /{ }^{39} \mathrm{Ar}$. Ainda segundo este autor, a partir de semelhanças litológicas, seis unidades magmáticas são reconhecidas, e podem ser agrupadas em três grupos que denotam a Suíte Magmática Ipojuca (SMI): i) rochas plutônicas a hipabissais, representadas pelo Granito do Cabo, incluindo a suas variedades graníticas e monzoníticas, e brechas magmáticas; ii) rochas vulcânicas (derrames, soleiras, plugs, domos, lacólitos) de composição variando desde basalto/traquiandesito a riolito, e fluxos piroclásticos (ignimbritos); e iii) diques riolíticos tardios, intrusivos nas demais unidades.

Almeida (2003) e Córdoba et al. (2007) apontam para a contemporaneidade da SMI com a Formação Cabo, mesmo que alguns pulsos ígneos sejam mais jovens. Estes autores sugerem ainda que o magmatismo foi contemporâneo à tectônica distensional do estágio rifte, e está associado com pulsos térmicos.

\subsection{Formação Estiva}

A Formação Estiva, segundo Lima Filho (1998), é constituída por três níveis de calcários maciços: o nível superior, caracterizado por calcários de coloração creme, por vezes dolomitizados; o nível intermediário, com calcários creme a cinza, e argilosos; e um nível inferior, de granulometria muito fina, com coloração cinza esbranquiçada. Os calcários maciços podem estar associados a siltitos/ argilitos escuros e folhelhos esverdeados (Lima Filho, 1998; Córdoba et al., 2007). A deposição dessa sequência marca o início da fase drift da bacia, e segundo dados paleontológicos (associação palinológica) obtidos na porção onshore, uma idade Cenomaniana inferior -
Turoniana pode ser atribuída a essa plataforma carbonática (Córdoba et al., 2007).

Essa formação inclui leques costeiros e deltas nas porções proximais, sistemas deposicionais carbonáticos de águas rasas e de alta energia que se conectam a sistemas siliciclásticos, depositados em rampa homoclinal em direção à costa, gradando para uma plataforma carbonática de águas rasas e baixa energia em offshore (Córdoba et al., 2007). Barbosa et al. (2008) salientam que a deposição dos carbonatos da Formação Estiva ocorreu em um ambiente de lagunas costeiras e construções recifais com forte influxo terrígeno e alta energia, ainda que em cenário de plataforma rasa.

\subsection{Formação Algodoais}

As rochas que constituem a Formação Algodoais compreendem conglomerados predominantemente polimíticos (fragmentos de quartzo, rochas do embasamento cristalino e, mais caracteristicamente, vulcânicas) e arenitos com intercalações de argilitos, possuindo um padrão entrelaçado a meandrante (Córdoba et al., 2007).

Almeida (2003) destaca duas características importantes da Formação Algodoais: i) os ciclos de sedimentação com granodecrescência ascendente são bem marcados (gradação normal) onde, por vezes, ocorrem níveis lateríticos ou concreções ferruginosas que marcam o início e/ou final desses ciclos, com exposição subaérea e um hiato da sedimentação fluvial; e ii) as estratificações cruzadas acanaladas e, por vezes, tabulares, que são proporcionais à diminuição da granulometria, chegando até a laminações plano-paralelas nos níveis argilosos.

A Formação Algodoais apresenta uma discordância angular ou erosional bem marcada sobre as rochas siliciclásticas da Formação Cabo, e/ou as rochas da Suíte Magmática Ipojuca, ou ainda sobre os carbonatos da Formação Estiva, em geral, subaflorantes (Almeida, 2003; Cruz et al., 2003).

Córdoba et al. (2007) sugerem uma idade, possivelmente, Paleógena, devido à ocorrência de apatita detrítica, com idade de 78,0 $\pm 6 \mathrm{Ma}$ 
pelo método de traços de fissão. Contudo, pelo fato de a Formação Algodoais estar posicionada sobre a Formação Estiva e sotoposta à Formação Barreiras, Lima Filho (1998) considera, para a Formação Algodoais, um intervalo de idade pós-Turoniana alcançando, possivelmente, o Neógeno.

\section{Métodos}

Integrar ferramentas disponíveis, como dados topográficos e geofísicos, proporciona grande contribuição à caracterização geológica, principalmente, em áreas que oferecem obstáculos aos trabalhos de campos, assim como ocorre na porção centro-sul da Bacia Pernambuco, onde, principalmente, o intemperismo químico e processos erosivos têm grande atuação, promovendo a escassez de afloramentos. Diante disso, este trabalho focou numa metodologia integrada de análise e interpretação de dados geomorfológicos, magnéticos, juntamente a dados adquiridos em campo.

A Folha topográfica Sirinhaém, em escala 1:25.000 (SUDENE, 1974) foi georreferenciada em ambiente de sistema de informações geográficas $(\mathrm{SIG})$, servindo como base altimétrica. A partir desta folha topográfica, foi realizada a vetorização de curvas de níveis e pontos cotados altimétricos que foram usados para a geração de um modelo digital de elevação (MDE) a partir do método de triangulação chamado Triangulated Irregular Network (TIN). Este método compreende uma ferramenta de modelagem e análise de dados sendo que, no caso de dados altimétricos, proporciona a conexão dos mesmos por meio da criação de várias facetas triangulares (Peucker et al., 1978).

Imagens multiespectrais orbitais gratuitas, obtidas via o aplicativo Google Earth PRO v. 7.3.2.5491, foram usadas para a interpretação de drenagem, lineamentos, estradas e morfologia, em conjunto com as informações da Folha topográfica Sirinhaém. Compreendem imagens de alta resolução espacial $(0,31$ a 0,50 m) da empresa Digital Globe, abrangendo composições coloridas de bandas de sensores como Geoeye-1 e WorldView-2 a 4.
Dados magnéticos terrestres usados são referentes àqueles coletados por Arrais et al. (2010), mediante uso de um magnetômetro Fluxgate MF-2 (Scintrex). Esses autores realizaram medidas verticais do campo magnético em 185 estações, com espaçamento médio de 1000 m, cobrindo toda a área da Folha Sirinhaém (1:25.000). A partir do interpolador curvatura mínima (Briggs, 1974), foram gerados grids com células de $250 \mathrm{~m}$ das imagens do campo magnético anômalo e da amplitude do sinal analítico, que permite centralizar a posição de corpos e feições magnéticos crustais (Roest et al., 1992).

A etapa de campo consistiu na identificação e descrição de 44 afloramentos, com levantamentos de seções estratigráficas. Foram coletadas 13 amostras e, destas, 11 foram selecionadas para a confecção de seções delgadas.

\section{Resultados}

\subsection{Interpretação do modelo digital de elevação (MDE-TIN)}

Por meio do modelo digital de elevação (MDE-TIN) de parte da Folha Sirinhaém, foram interpretados os padrões de drenagem e feições geomorfológicas, incluindo a definição de principais lineamentos de drenagem que possuem três direções preferenciais (NNW-SSE, N-S e NE-SW) (Fig. 2A).

Também foi possível delimitar quatro domínios geológicos através da integração de dados de trabalhos prévios disponíveis (e.g. Almeida, 2003) com a geomorfologia local (Fig. 2B), a saber: i) o embasamento cristalino, que ocorre na porção oeste e NW da área, e que apresenta cotas altimétricas mais elevadas, variando entre 80 e 110 m; ii) o riolito da SMI, que trata-se de um corpo alongado NW-SE, com cotas altimétricas entre 70 e 90 m; iii) a região das formações Cabo, Estiva e Algodoais, indiferenciadas sob o ponto de vista topográfico (cotas de até 80 m), e inserida na porção central e nordeste da área; e iv) a área de terraços marinhos, mangues, sedimentos aluvionares e/ 
ou flúvio-lagunares, localizada nas porções leste, sudeste e centro-oeste, e que é representada por cotas altimétricas mais rebaixadas e inferiores a $10 \mathrm{~m}$.

\subsection{Interpretação de dados magnéticos}

A partir da imagem da amplitude do sinal analítico, foram interpretados lineamentos magnéticos com as direções preferenciais NESW e NW-SE, além de 26 estruturas circulares (anomalias positivas circulares) inseridas na porção leste, central e SW da área, e que foram interpretadas como possíveis estruturas vulcânicas por Arrais et al. (2010) (Fig. 3).

As estruturas magnéticas lineares observadas na área de estudo (Fig. 3) caracterizam, principalmente, falhamentos normais de direção NE-SW e NNW-ESE, e falhamentos de transferência/transcorrência de direção NW-SE. Em geral, as falhas normais e de transferência/transcorrência marcam o contato entre as unidades litoestratigráficas.

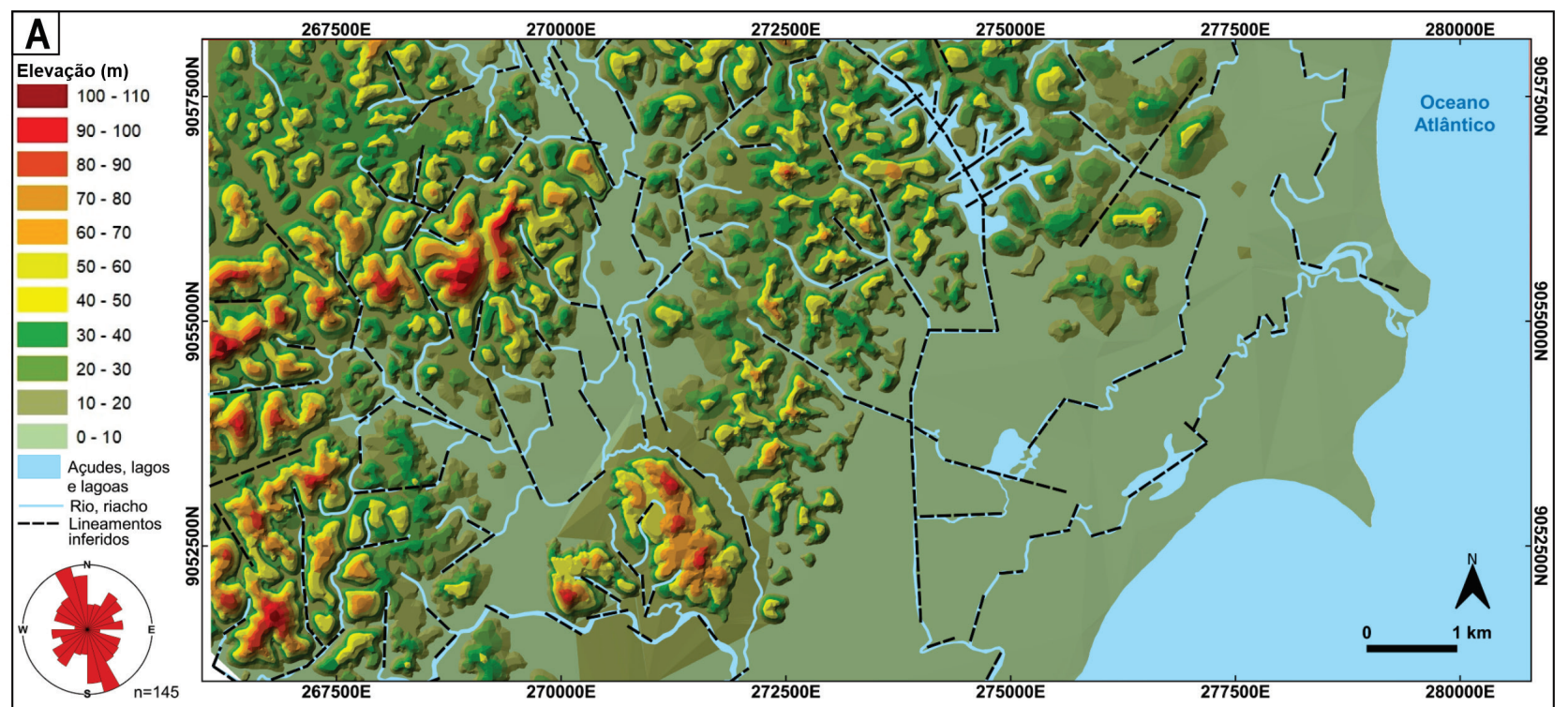

B

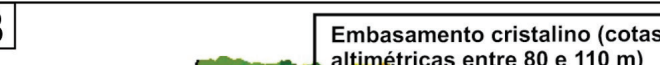

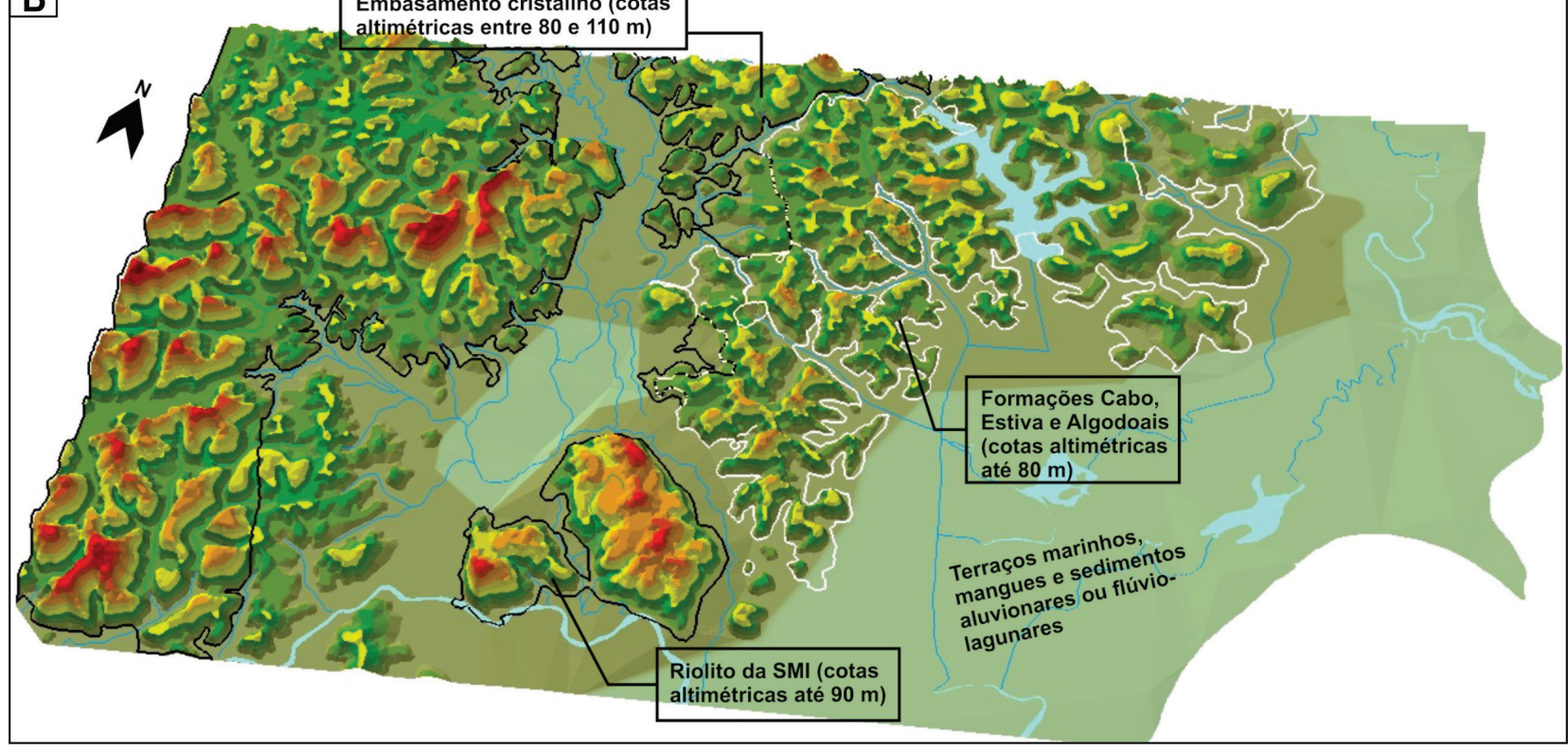

Figura 2. Modelo digital de elevação (MDE-TIN) de parte da Folha Sirinhaém. A) Lineamentos de drenagem interpretados; B) Visão em perspectiva da área de estudo e compartimentação das principais unidades geológicas obtidas por meio da integração de dados geológicos previamente publicados (e.g. Almeida, 2003).

Figure 2. Digital elevation model (DEM-TIN) of part of Sirinhaém Sheet. A) Interpreted drainage lineaments; B) Perspective view of the studied area and discrimination of the main geological units based on the integration of previously published geological data (e.g. Almeida, 2003). 


\subsection{Caracterização geológica da área estudada}

A partir da integração de dados de campo, magnetométricos, do MDE-TIN, e interpretações estruturais, foi produzido o mapa geológico na escala 1:25.000 da área de estudo (Fig. 4), onde foram cartografadas as unidades geológicas descritas a seguir.

\subsubsection{Embasamento cristalino}

O embasamento cristalino aflorante ocorre no setor oeste e NW da área de estudo (Fig. 4). É composto por granitos, gnaisses e migmatitos em processo de alteração intempérica intensa. Assim sendo, o embasamento é discriminado pela presença de solos e/ou rochas alteradas, de coloração amarronzada, com bandamento mineralógico, por vezes, visível (Fig. 5A), ou stone lines de quartzo (Fig. 5B e C).

\subsubsection{Formação Cabo}

A Formação Cabo ocorre na porção SW da área (Fig. 4), em contato com as rochas do embasamento cristalino, SMI e a Formação Algodoais. O contato com o embasamento é delimitado por falhamentos normais ou de rejeito direcional/oblíquo, conforme anteriormente descrito por Lima Filho (1998) e Almeida (2003). Ao se distanciar da região de falhas de borda, ao longo da bacia, é possível notar que a granulometria dos fragmentos conglomeráticos tende a diminuir e há um aumento na quantidade de matriz.

A Formação Cabo é constituída, predominantemente, por sedimentos retrabalhados, provenientes das rochas do embasamento (xistos, gnaisses, migmatitos, granitos e pegmatitos). São ortoconglomerados e paraconglomerados mal selecionados, subarredondados a subangulosos, com granulação variando de seixos a matacões (Fig. 6A e B). Apresentam matriz silte/argilosa à arenosa, com predomínio desta última. A matriz é composta por feldspatos, quartzo, e fragmentos líticos. Ocorrem também, associadas a estes, intercalações de folhelhos vermelhos (Fig. 6C). Para Collinson (1996), a presença de intercalações de sedimentos finos pode indicar a ocorrência

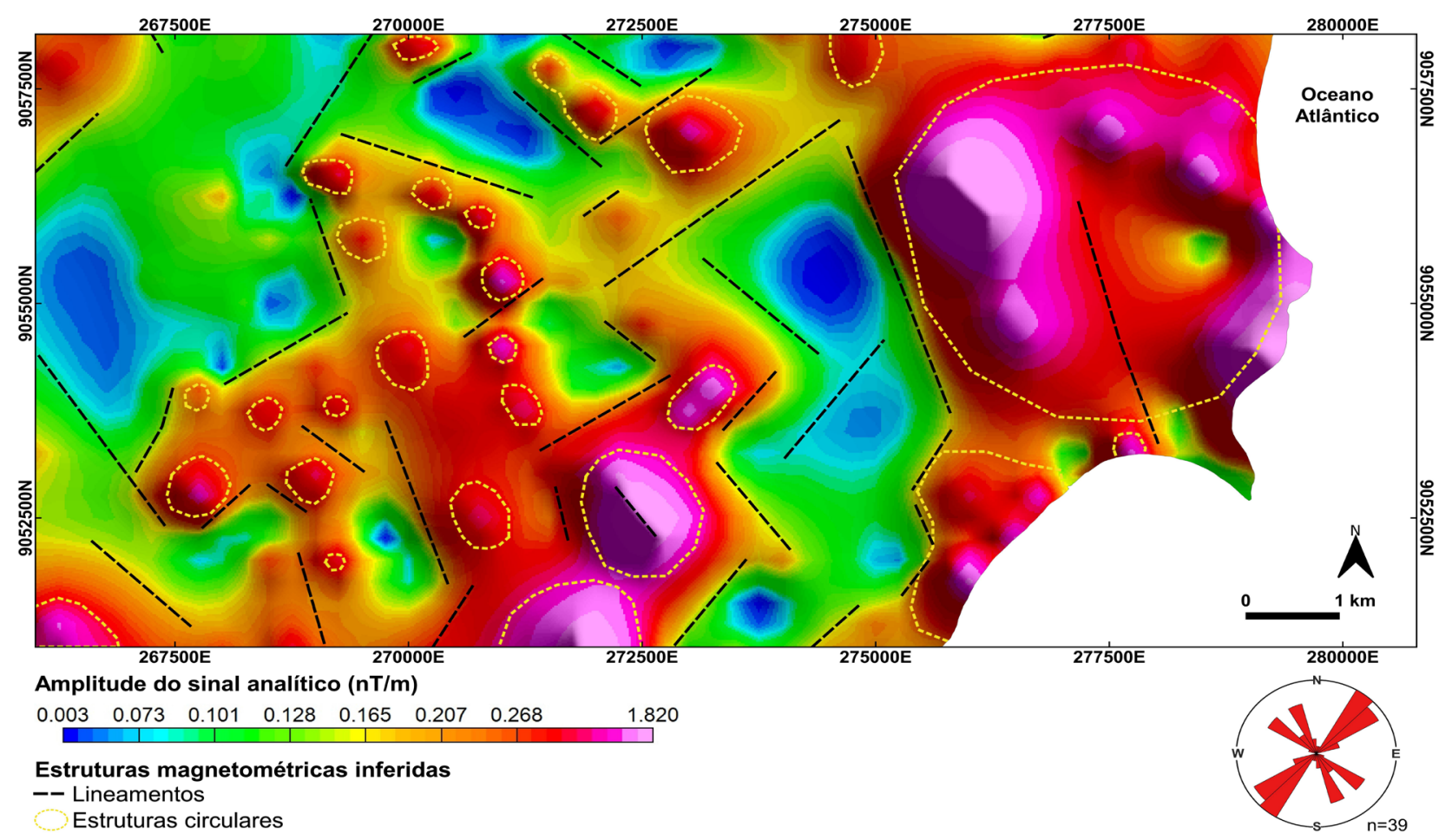

Figura 3. Estruturas magnéticas interpretadas na imagem da amplitude do sinal analítico. As linhas tracejadas amarelas demarcam a borda de corpos com alto gradiente magnético, possivelmente, estruturas vulcânicas.

Figure 3. Magnetic structures interpreted in the image of the analytic signal amplitude. The dashed yellow lines demarcate the edge of bodies with a high magnetic gradient, possibly volcanic structures. 
de um transporte por fluxos hiperconcentrados, sendo que os níveis conglomeráticos, nos quais os clastos "flutuam" numa matriz arenosa, mostram imbricação.

A litologia aqui descrita da Formação Cabo corresponde à fácies proximal descrita por Lima Filho (1998), que foi depositada em sistema de leques aluviais.

\subsubsection{Suíte Magmática Ipojuca}

A SMI ocorre na porção centro-sul da área (Fig. 4) e compreende riolitos, basaltos e ignimbritos. São corpos intrusivos ou derrames associados às formações Cabo e Algodoais e ao embasamento cristalino.

Os riolitos possuem textura afanítica, são bastante fraturados e apresentam uma "crosta" marrom avermelhada devido aos agentes intempéricos, principalmente, químicos atuantes na região (Fig. 7A e B). Lima Filho (1998) sugere que os riolitos designam o primeiro evento vulcânico na bacia, pouco expressivo ao longo dessa. Os basaltos possuem textura afanítica e coloração preta (Fig. 7C). O intemperismo químico atuante nos basaltos produz um solo de coloração avermelhada intensa (Fig. 7D e E).

Também é observado basalto/traquito(?) com minerais esbranquiçados, possivelmente zeólitas, indicando um vulcanismo de superfície. Sotoposto ao basalto/traquito(?), ocorre ignimbrito, sendo este caracterizado por fragmentos de feldspatos e quartzo, subangulosos a arredondados, dispostos numa matriz fina argilosa, afanítica, de coloração cinza arroxeada. Rocha vulcânica ácida ocorre no topo desse afloramento (Fig. 7F).

O evento vulcânico tardio presente na Bacia Pernambuco possui uma distribuição irregular e é pouco expressivo, sendo constituído, frequentemente, por diques riolíticos de idade incerta (Lima Filho, 1998; Nascimento, 2003). Nascimento (2003) sugere que embora a maioria das rochas da SMI tenham idades entorno de $\pm 102,0 \mathrm{Ma}$, relacionadas à seção rifte, pelo menos parte do magmatismo foi sincrônico com uma sedimentação siliciclástica da Formação Cabo e que, possivelmente, os ignimbritos podem ter cronocorrelação com os diques tardios riolíticos.

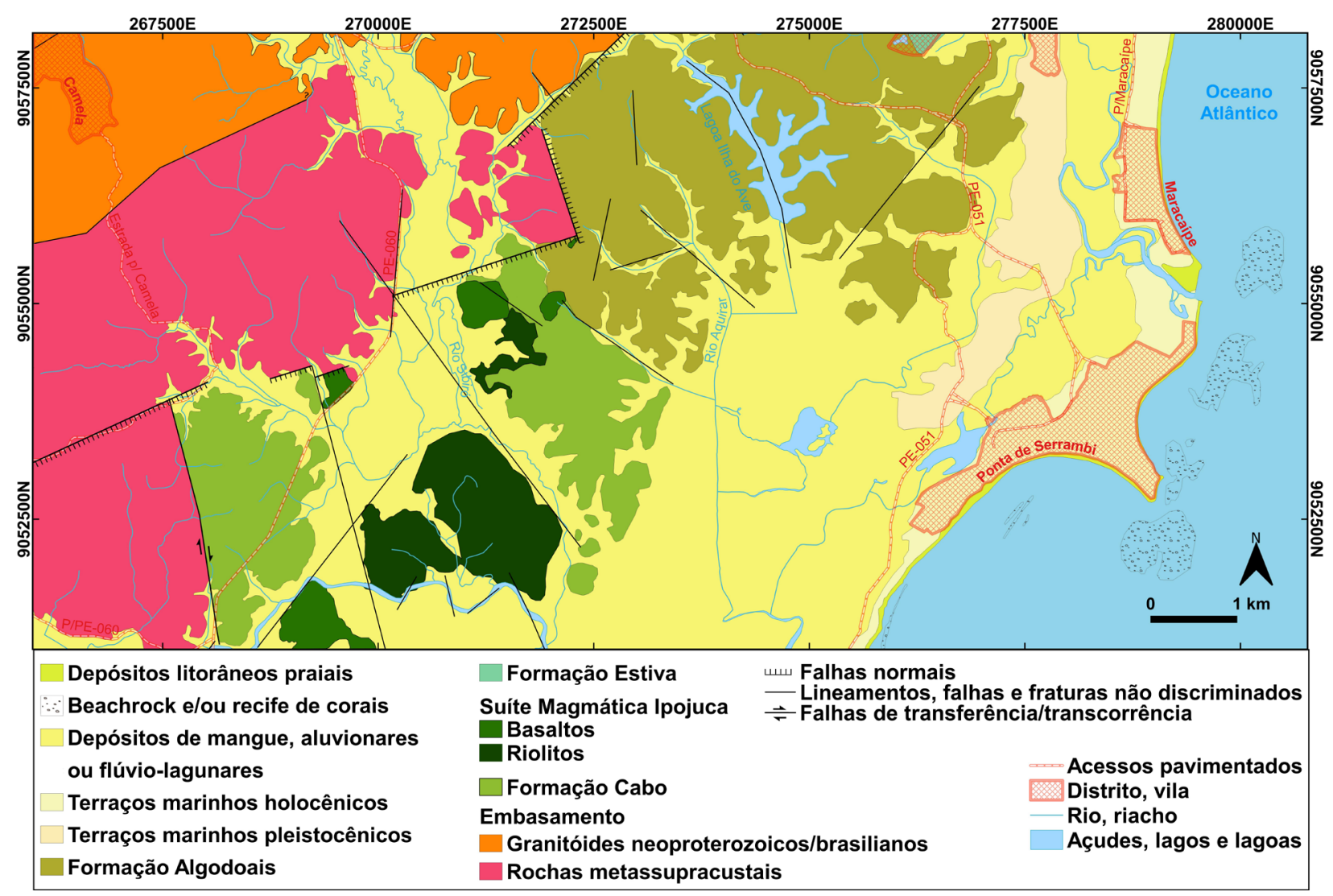

Figura 4. Mapa geológico (1:25.000) da porção centro-sul da Bacia Pernambuco (Passos, 2019).

Figure 4. Geological map (1: 25,000) of the south-central portion of the Pernambuco Basin (Passos, 2019). 

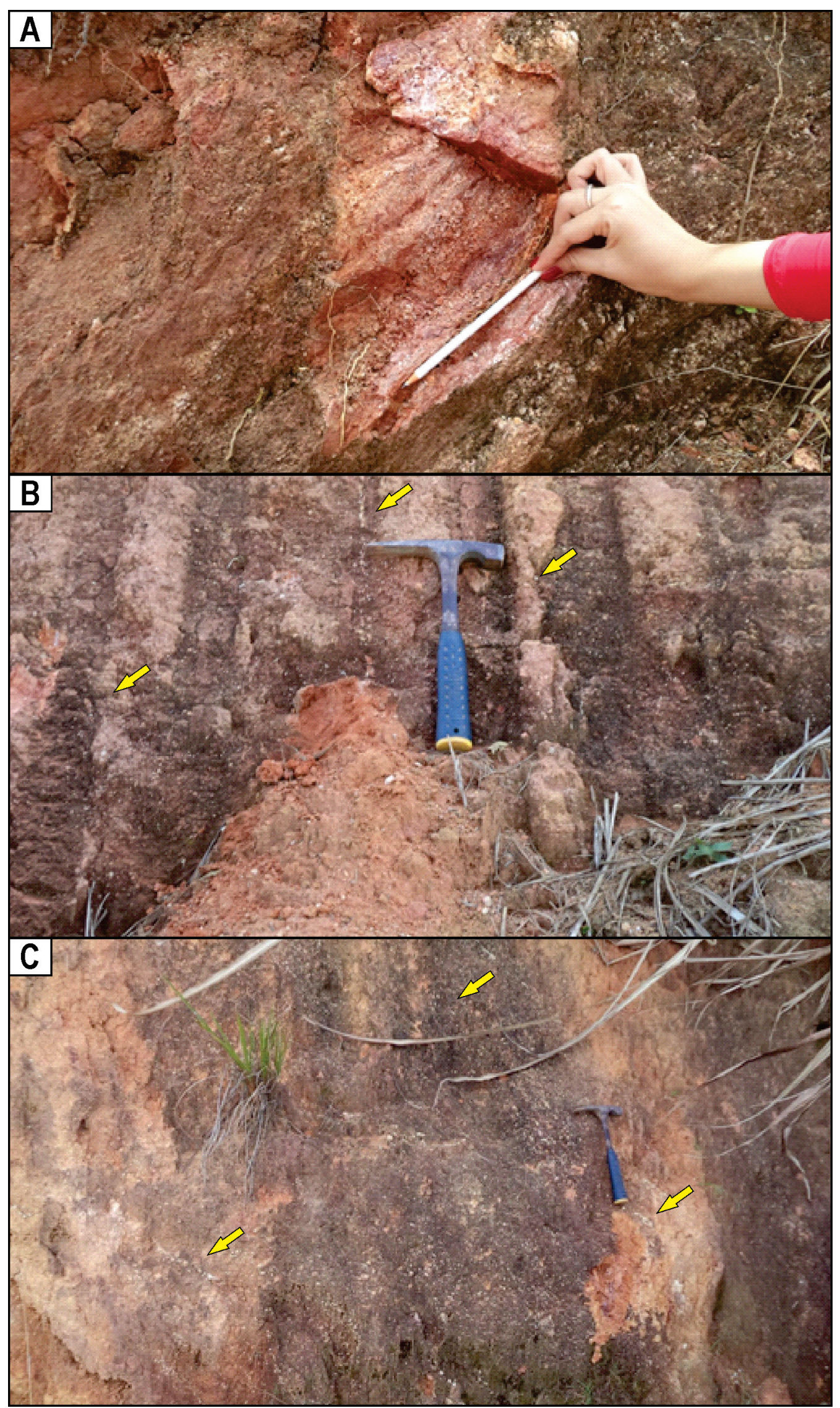

Figura 5. Afloramentos do embasamento cristalino. A) Rocha bastante alterada, onde é possível observar bandamento mineralógico (migmatito?); B e C) Solos relacionados a rochas do embasamento cristalino apresentando stone lines de quartzo (ver setas amarelas).

Figure 5. Outcrops of the crystalline basement. A) Highly altered rock, observing a mineralogical banding (migmatite?); $B$ and $C$ ) Soils related to crystalline basement rocks showing quartz stone lines (see the yellow arrows). 


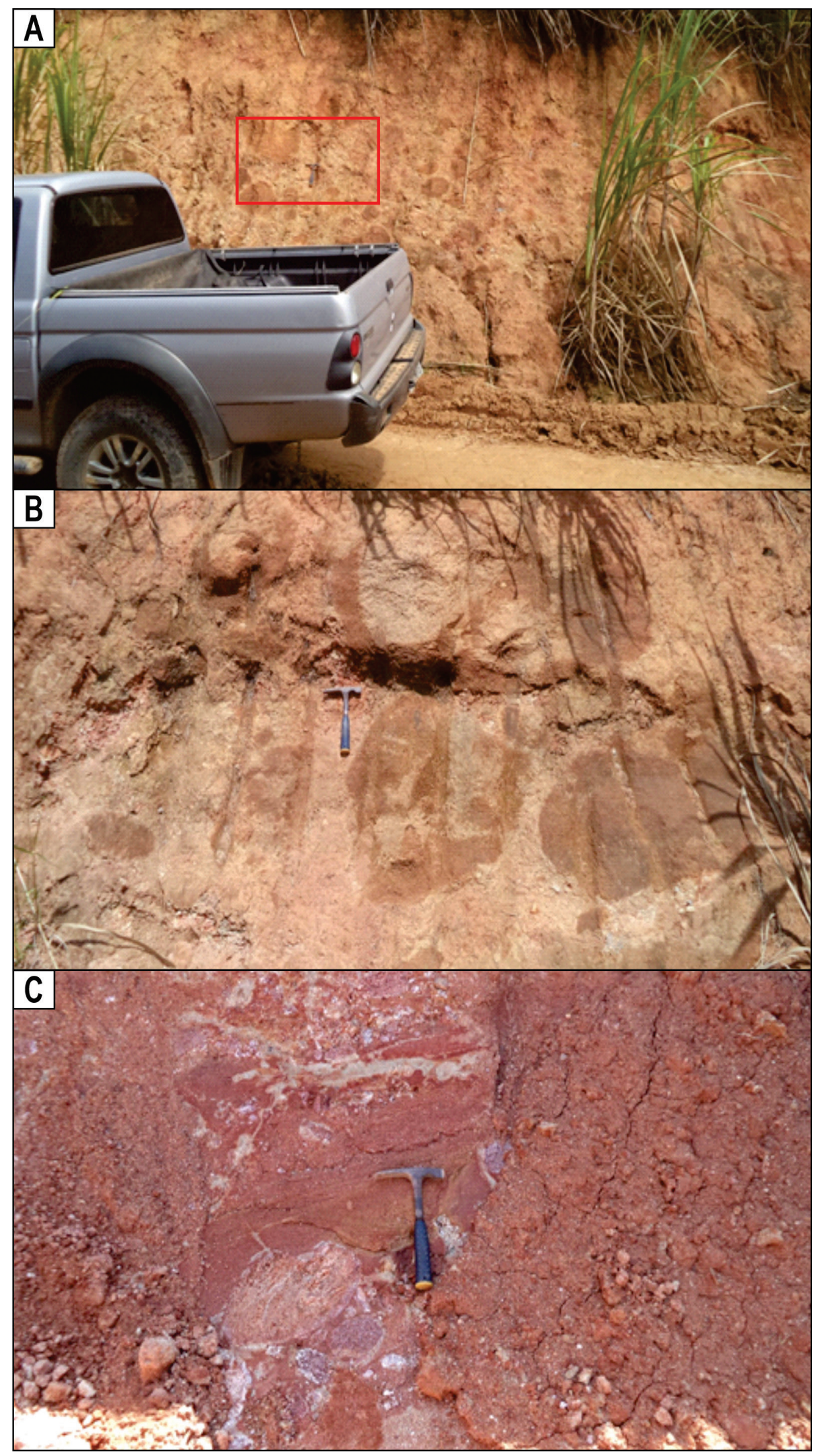

Figura 6. Afloramentos da Formação Cabo. A) Conglomerados mal selecionados, em processo de intensa ação intempérica, localizado no setor centro-NW da área; B) Detalhe desses conglomerados (vide retângulo vermelho na Fig. 6A); C) Conglomerado subaflorante (Formação Cabo) observado no setor SW da área de estudo, e intercalado com folhelhos vermelhos e clastos de rochas ígneas.

Figure 6. Outcrops of the Cabo Formation. A) Poorly sorted conglomerates, in an intense weathering process, and located in the central-NW sector of the area; B) Detail of these conglomerates (see red rectangle in Fig. 6A); C) Sub-outcropping conglomerate (Cabo Formation), described in the SW sector of the studied area, interspersed with red shales and clasts of igneous rocks. 


\subsubsection{Formação Estiva}

A Formação Estiva ocorre na porção NE da área (Fig. 4), em contato com arenitos da Formação Algodoais (Fig. 8A e B). São folhelhos verdes, calcíferos, de textura muito fina, com ausência de microfósseis. Os afloramentos desta formação são escassos e marcam a presença de uma plataforma carbonática na bacia.

\subsubsection{Formação Algodoais}

A Formação Algodoais ocorre na porção NE e centro-norte da área, em contato com as rochas do embasamento cristalino, SMI e das formações Cabo e Estiva. O contato com o embasamento cristalino é delimitado por falhamentos normais (Fig. 4).

Essa formação é constituída por arenitos médios a finos, além de argilitos. Os arenitos são moderadamente selecionados, amareloesbranquiçados, e compostos por grãos de quartzo subangulosos a subarredondados, além de matriz silte/argilosa, a exemplo do arenito fino que ocorre na porção NE da área, sobreposta aos folhelhos da Formação Estiva (Fig. 8A). Esta formação, por vezes, apresenta intercalações de lentes e/ou camadas de argilitos arroxeados (Fig. 9), além da ocorrência de arenitos arcoseanos (Fig. 10A e B).

Também é observada uma fácies sedimentar vulcanogênica (com intercalações de argilitos) na base (Fig. 10A). Em seção delgada, essa fácies é composta por biotita alterando para argilominerais, e fragmentos vulcânicos (?) dispostos numa matriz silte/argilosa (Fig. 10C). Em alguns afloramentos, esta formação é marcada por arenitos grossos amarelados, com lentes de quartzo fumê e estratificação cruzada acanalada.

A Formação Algodoais apresenta ciclos de sedimentação com granodecrescência ascendente bem marcada, previamente identificados por Almeida (2003), sendo que três desses ciclos foram observados na região em apreço (Fig. 11A). Por vezes, os ciclos apresentam níveis lateríticos ou concreções ferruginosas marcando o início e/ou final desses ciclos. Afloramentos de arenitos da Formação
Algodoais (hangingwall) associados com rochas vulcânicas (riolito ou basalto; footwall), ambos em processo de alteração intempérica avançada, também ocorrem estruturados em grábens (Fig. 11B).

Os arenitos finos, e/ou arcoseanos e/ou argilosos da Formação Algodoais apresentam, em geral, grãos de quartzo fraturados, subangulosos a subarredondados, moderadamente a mal selecionados. Os minerais minoritários são micas, fragmentos líticos, zircão, minerais opacos e turmalinas. Grãos de quartzos são mono e policristalinos, e apresentam contatos, predominantemente, pontuais e flutuantes. Alguns grãos de quartzo apresentam embainhamento, indicando uma possível origem vulcânica para esses grãos (Boggs Jr., 2009; Müller et al., 2009) (Fig. 10B, $12 \mathrm{~A}$ e B). A matriz destas rochas é silte/argilosa e/ou ferruginosa. Grãos de feldspatos são os minerais predominantes de arenitos arcoseanos ou argilosos e exibem grau elevado de alteração para argilominerais. Contudo, há o predomínio de arenitos argilosos nos poucos afloramentos acessíveis da Formação Algodoais nessa região.

\subsubsection{Depósitos quaternários}

Os depósitos quaternários equivalem aos terraços marinhos pleistocênicos e holocênicos, depósitos de mangue, aluvionares, flúvio-lagunares, beachrocks, recifes de corais, além de depósitos litorâneos praiais (Fig. 4). Foram delimitados espacialmente, a partir, principalmente, do uso de imagens de satélites de alta resolução espacial, estando presentes nas regiões com cotas altimétricas mais baixas.

\subsection{Estruturas circulares e sedimentação vulcanoclástica}

Com base na análise em perspectiva do MDE-TIN integrado ao mapa geológico (Fig. 13), é possível visualizar a relação da influência da variação topográfica com a ocorrência de grande parte das unidades geológicas. 


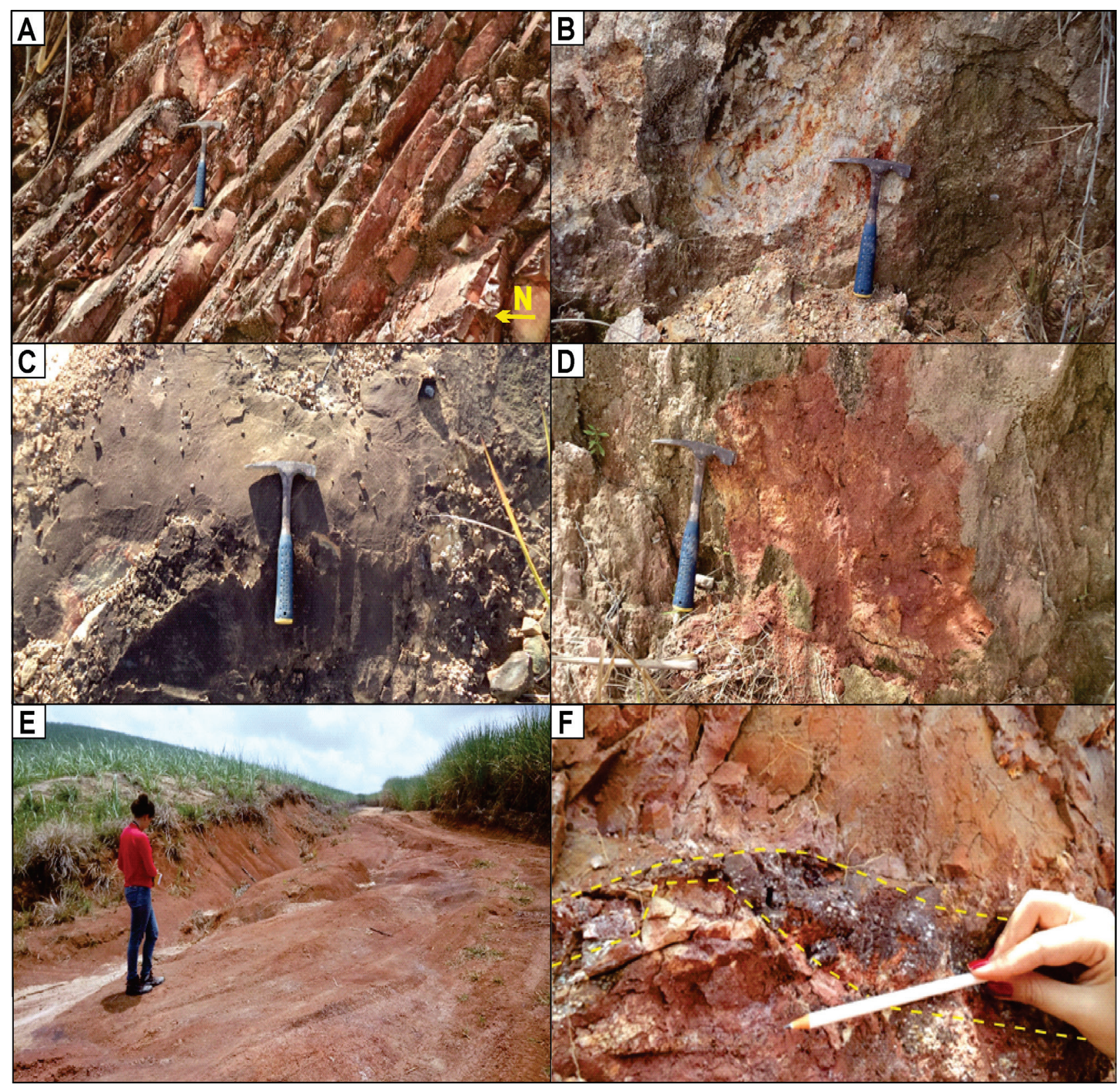

Figura 7. Afloramentos da SMI. A) Riolito fraturado, localizado a NE do município de Sirinhaém, com possível fluxo de magma para NW; B) Riolito bastante intemperizado, localizado no setor centro-sul da área; C) Derrame de basalto, situado no setor centro-SW; D) Solo avermelhado intenso, provavelmente, desenvolvido a partir da intemperização em dique basáltico; E) Solo avermelhado intenso localizado no setor centro-sul da região estudada, possivelmente, gerado a partir dos processos intempéricos em rochas basálticas; F) Detalhe de ignimbrito (delimitado pela linha amarela pontilhada) em contato com rocha vulcânica ácida, no topo, e basalto/traquito(?), na base.

Figure 7. Outcrops of the ISM (Ipojuca Magmatic Suite). A) Fractured rhyolite, located NE of the municipality of Sirinhaém, with the possible flow of magma to NW; B) Intensely weathered rhyolite, observed in the south-central sector; $C$ ) Basalt spill, located in the central-NW sector of the studied area; D) Intense reddish soil, probably developed from the weathering in a basaltic dike; E) Intense reddish soil inserted in the south-central sector, possibly generated from the weathering of basaltic rocks; F) Detail of ignimbrite (delimited by yellow dotted line) occurring in contact between acidic volcanic rock, at the top, and basalt/trachyte (?) at the base. 


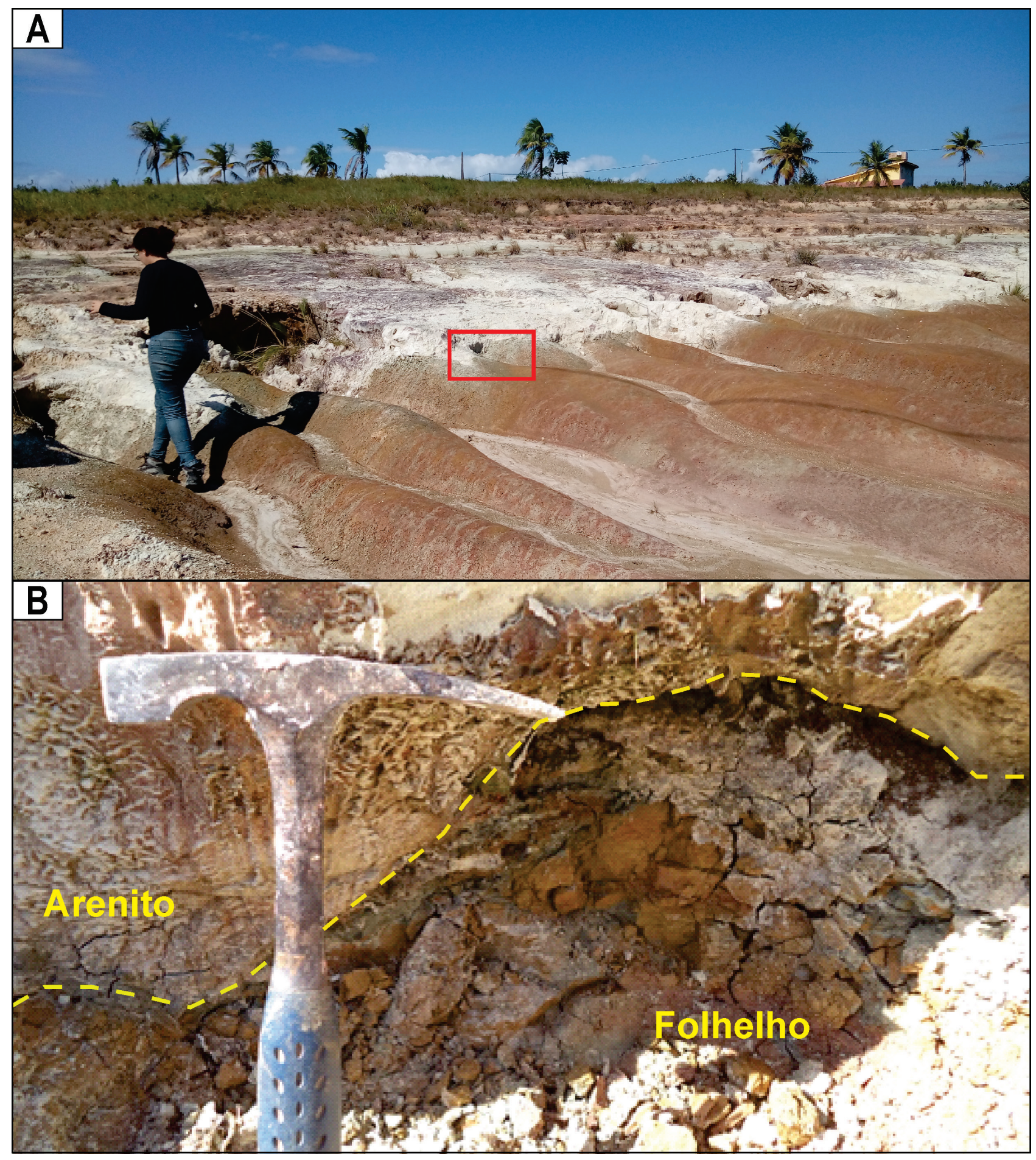

Figura 8. Exemplo de afloramento de rochas da Formação Estiva na área de estudo. A) Base do afloramento, marcada por folhelhos verdes da Formação Estiva, e topo caracterizado por arenito fino esbranquiçado da Formação Algodoais; B) Detalhe do contato entre as formações Estiva e Algodoais (vide linha amarela pontilhada) da porção do afloramento demarcada por retângulo vermelho na Fig. 8A.

Figure 8. Example of the rock outcropping from the Estiva Formation in the studied area. A) Basal portion of outcrop, marked by green shales from the Estiva Formation, and top characterized by fine-grained whitish sandstone from the Algodoais Formation; B) Detail of the contact between Estiva and Algodoais formations (see the yellow dotted line), related to the outcrop portion highlighted by red rectangle in Fig. $8 \mathrm{~A}$. 


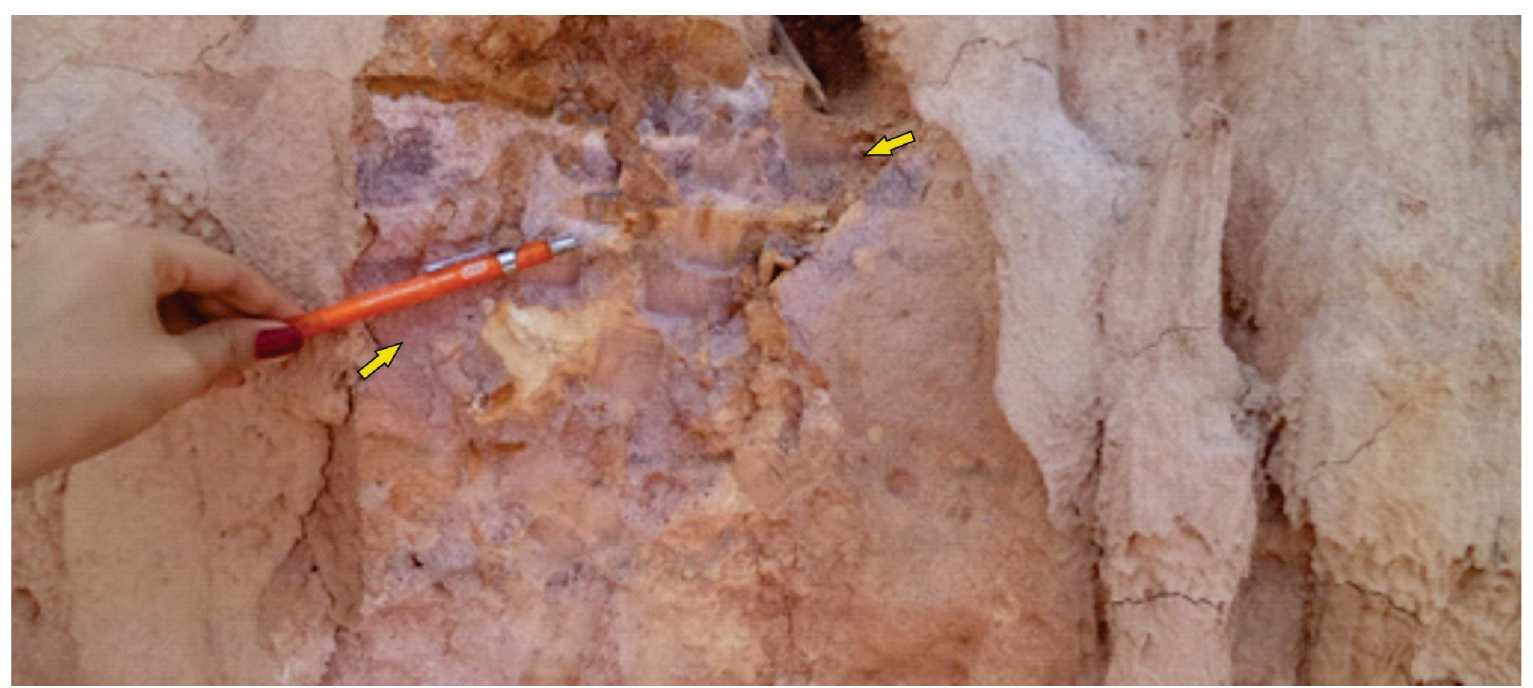

Figura 9. Afloramento da Formação Algodoais, com destaque para o arenito médio, amarelo-esbranquiçado, mal selecionado, intercalado com argilito arroxeado (setas amarelas).

Figure 9. Outcrop of the Algodoais Formation, highlighting the medium-grained whitish-yellow sandstone, poorly sorted and interspersed with purplish claystone (yellow arrows).

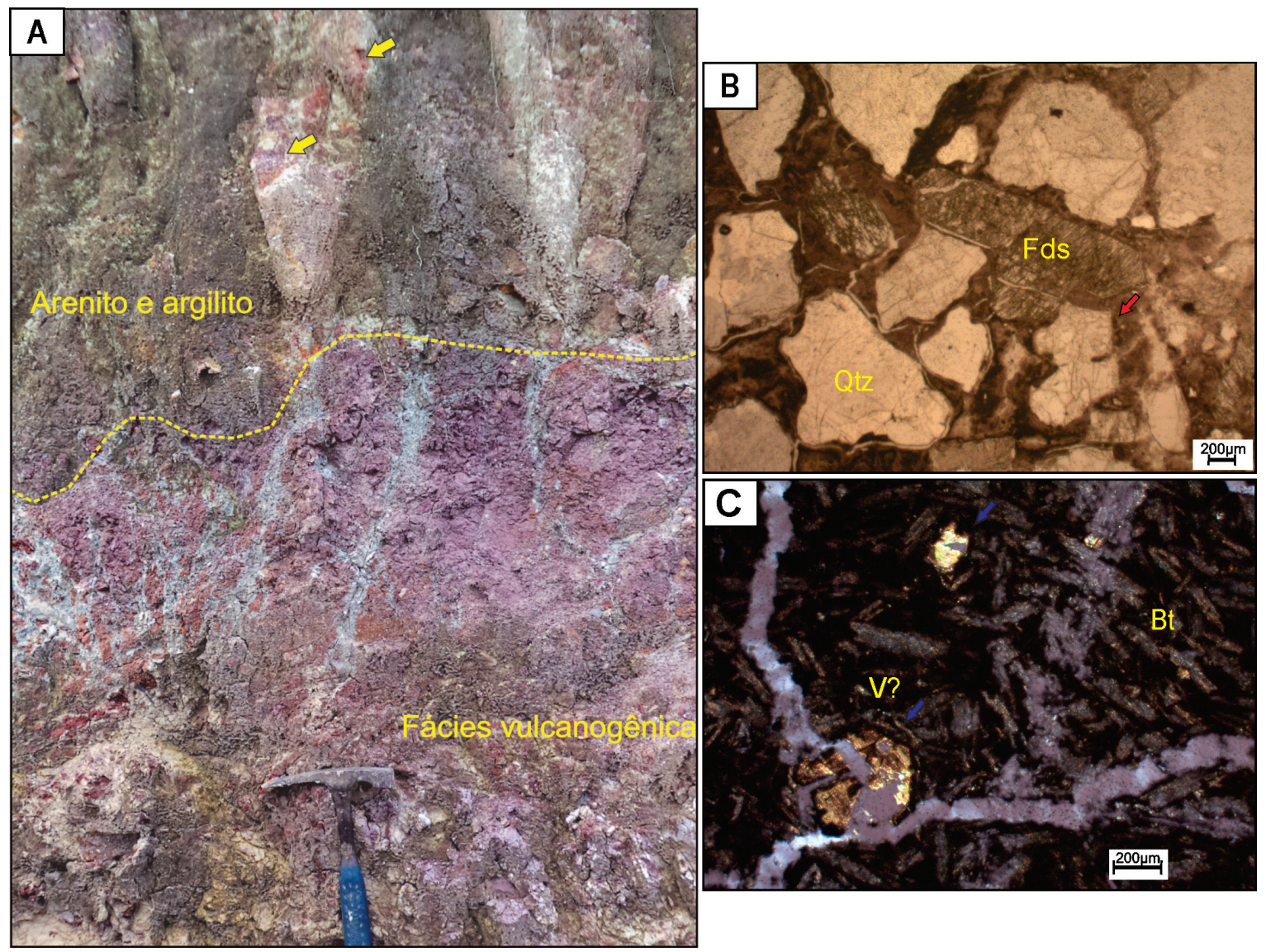

Figura 10. Detalhe de afloramento da Formação Algodoais marcado por: A) Arenitos e argilitos (setas amarelas), no topo, em associação a uma fácies sedimentar vulcanogênica localizada na base (vide delimitação em linha amarela pontilhada); B) Fotomicrografia de arenito arcoseano (luz transmitida, nicóis paralelos), e exemplo de grão de quartzo apresentando embainhamento (seta vermelha); C) Fotomicrografia da fácies vulcanogênica composta por biotita (Bt), possíveis fragmentos vulcânicos $\left(\mathrm{V}_{?}\right.$, indicado pelas setas azuis), e matriz silte/argilosa (luz transmitida, nicóis cruzados). $\mathrm{Qtz}=$ quartzo, Fds = feldspato.

Figure 10. Detail of Algodoais Formation outcrop marked by: A) Sandstones and claystones (yellow arrows), at the top, associated with volcanogenic sedimentary facies located at the base (see the delimitation in dotted yellow line); B) Photomicrograph of arcosean sandstone (transmitted light, parallel nicols), and example of quartz grain showing embayment (red arrow); C) Photomicrograph of the volcanogenic facies composed of biotite (Bt), possible volcanic fragments $\left(V_{7}\right.$ indicated by blue arrows), and a silty/clay matrix (transmitted light, crossed nicols). Qtz = quartz, Fds = feldspar. 


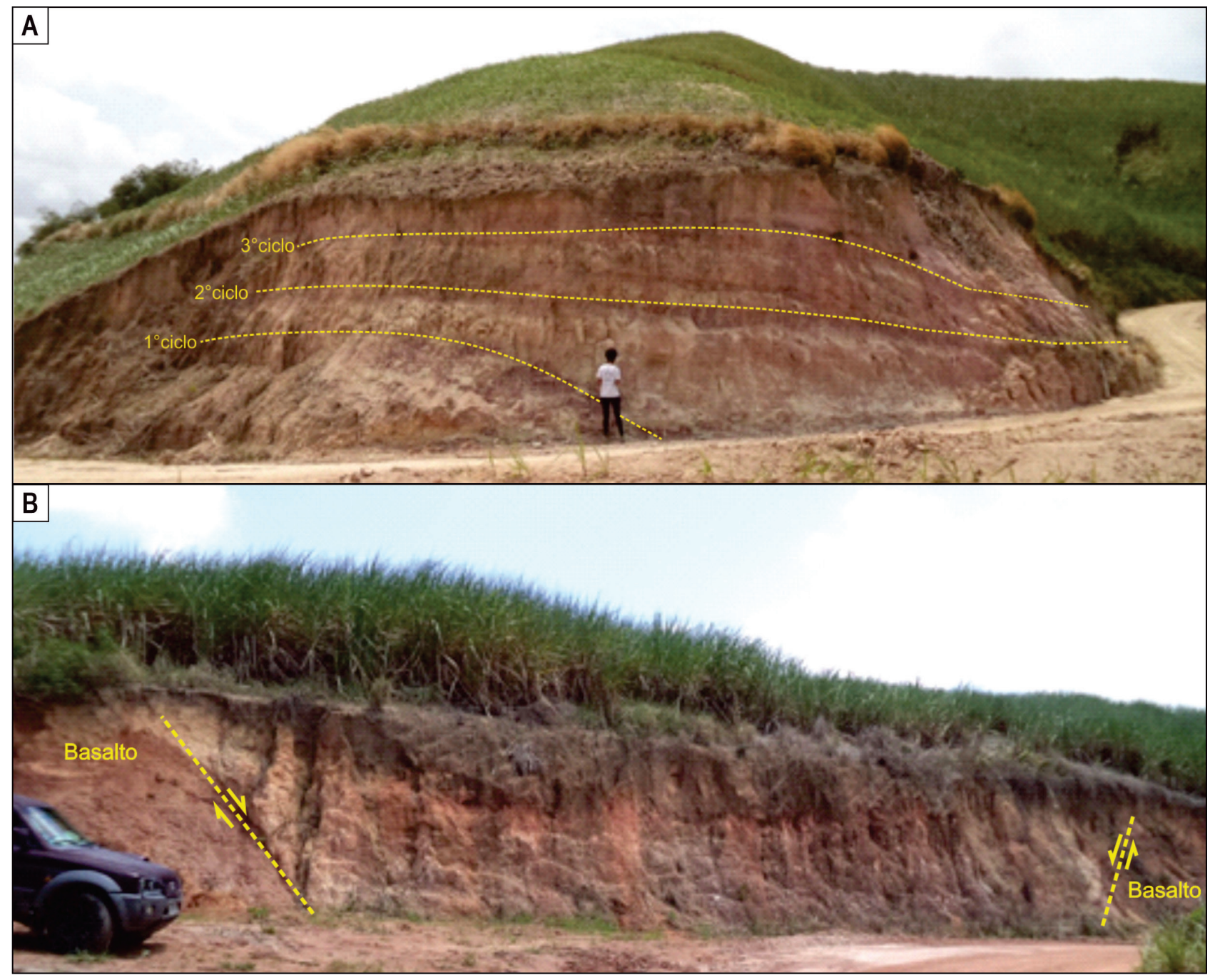

Figura 11. Vista geral de afloramentos da Formação Algodoais. A) Indicação de três ciclos de sedimentação com granodecrescência ascendente; B) Ocorrência de gráben, em que o footwall é constituído por basalto e, o hangingwall é composto por arenito fino de coloração amarelada, ambos em processo de alteração intempérica avançada.

Figure 11. General view of outcrops from the Algodoais Formation. A) Indication of three sedimentation cycles with ascending grain size; B) Occurrence of graben, in which the footwall is composed of basalt, and the hangingwall is marked by yellowish fine-grained sandstone, both undergoing an advanced weathering process.

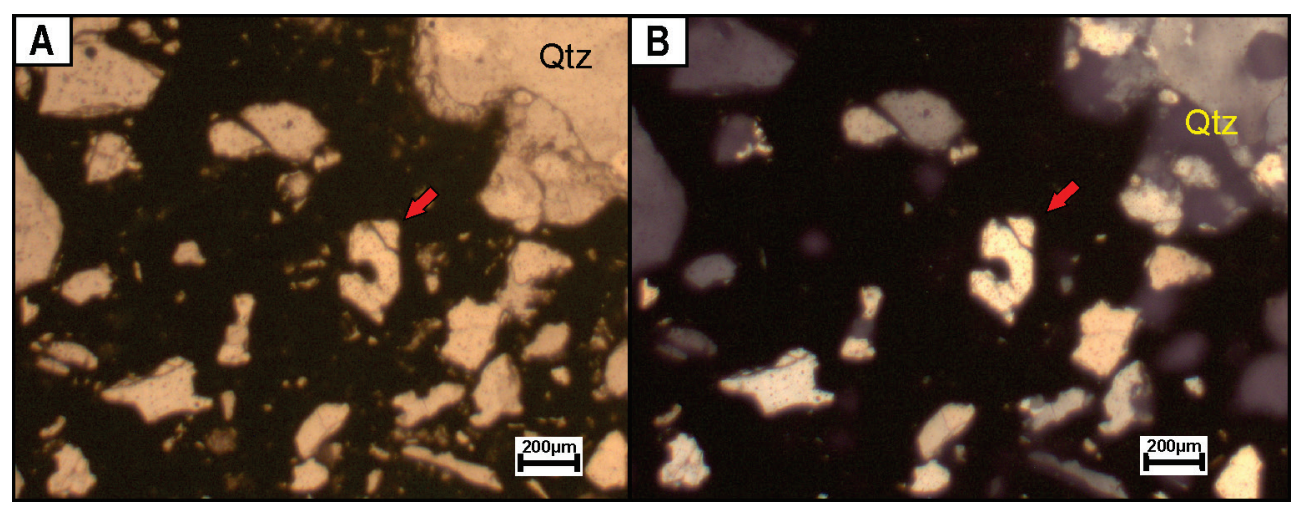

Figura 12. Fotomicrografias (luz transmitida) de arenito argiloso da Formação Algodoais, marcado por grãos de quartzo apresentando embainhamento (seta vermelha), indicando uma possível origem vulcânica para estes. A) Nicóis paralelos; B) Nicóis cruzados. Qtz = quartzo.

Figure 12. Photomicrographs (transmitted light) of clayey sandstone from the Algodoais Formation, marked by quartz grains showing embayment, indicating a possible volcanic origin. A) Parallel nicols; B) Crossed nicols. Qtz = quartz. 
O embasamento cristalino se destaca das demais unidades por estar localizado onde as cotas altimétricas são mais elevadas (cotas altimétricas entre 80 e 110 m), na porção oeste e NW da área, enquanto as unidades litoestratigráficas pertencentes à Bacia Pernambuco são distinguidas visualmente por serem marcadas por cotas altimétricas, em geral, inferiores às da região do embasamento.

A integração do mapa geológico (combinado com o MDE-TIN) com a imagem da amplitude do sinal analítico em perspectiva está mostrada na figura 13, assim como a posição de dezesseis pontos de campo referentes aos afloramentos catalogados no presente trabalho acerca da ocorrência de basaltos e riolitos da SMI, além daqueles de fácies sedimentar vulcanogênica que ocorrem associados com a Formação Algodoais. Observa-se que estes pontos de campo, indicados pelas projeções em linhas verticais na figura 13 (linhas em branco, representando os afloramentos da SMI, e linhas em amarelo, referentes aos afloramentos da Formação Algodoais), estão dispostos próximos às estruturas circulares magnéticas, marcadas por altos gradientes de amplitude do sinal analítico, indicando, possivelmente, tratar-se de pelo menos dois grandes centros vulcânicos,

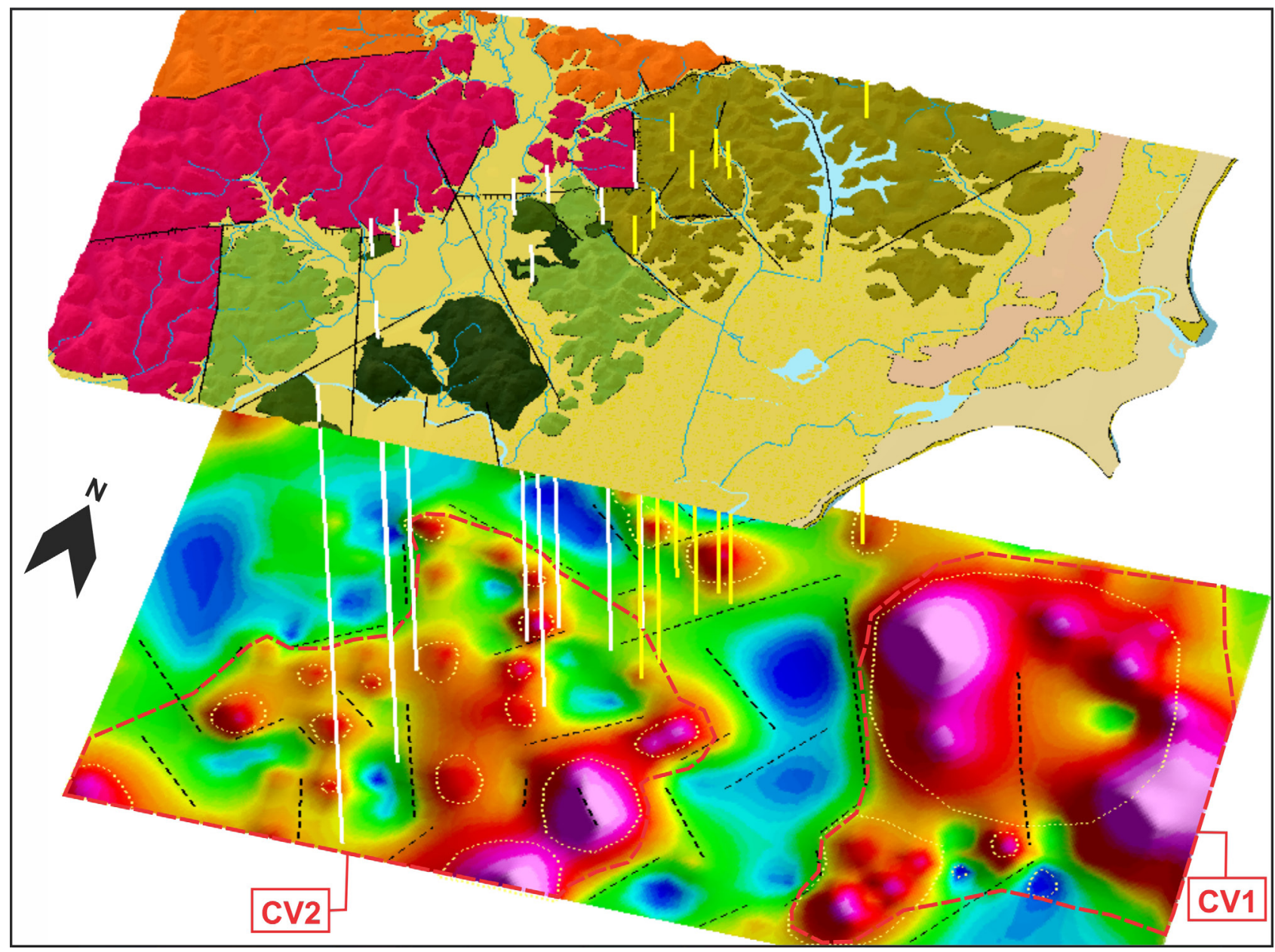

Figura 13. Vista em perspectiva da imagem da amplitude do sinal analítico e do mapa geológico (1:25.000) integrado com o MDE-TIN. Os pontos de campo referentes a basaltos e riolitos da SMI (projeção nas linhas brancas) e os pontos referentes a rochas da Formação Algodoais (projeção nas linhas amarelas) estão indicados. Estruturas circulares magnéticas estão delimitadas pelo tracejado em amarelo, enquanto o tracejado em vermelho indica dois possíveis grandes centros vulcânicos (CV1 e CV2). Exagero vertical: 3X. Legenda da imagem da amplitude do sinal analítico e do mapa geológico pode ser vista, respectivamente, na figura 3 e 4.

Figure 13. Perspective view of the image of analytic signal amplitude and the geological map (1:25,000 scale) integrated with the DEM-TIN. The field points are associated with basalts and rhyolites from the IMS (vertical white lines), and with rocks from the Algodoais Formation (vertical yellow lines). Circular magnetic structures are delimited by yellow dashed lines, while the red dashed lines indicate two possible large volcanic centers (CV1 and CV2). Vertical exaggeration: 3X. Legend of the image of the amplitude of the analytical signal and the geological map can be seen, respectively, in figures 3 and 4. 
sendo um localizado na porção leste, em direção à porção offshore da bacia e, consequentemente, ao Platô de Pernambuco (centro vulcânico CV1), e outro inserido na porção centro-sudoeste da área (centro vulcânico CV2).

As estruturas circulares vistas na imagem da amplitude do sinal analítico (Fig. 3 e 13), possivelmente, representam centros vulcânicos que, segundo Arrais et al. (2010), podem ser separados em dois grupos de anomalias. As anomalias com centros negativos retratam possíveis diques anelares, enquanto as anomalias de centros positivos podem representar condutos vulcânicos do tipo necks ou lacólitos. A maioria dessas estruturas não pode ser observada em campo por ocorrerem subjacentes às coberturas quaternárias. Em concomitância às assinaturas circulares magnéticas observadas na área remotamente, outros trabalhos, por exemplo, Santos et al. (2011), empregando dados magnéticos e gravimétricos da área continental e oceânica, propuseram que o magmatismo presente na Bacia Pernambuco estaria associado a uma megaestrutura circular presente no Platô de Pernambuco (pluma mantélica), localizada em frente às praias de Serrambi e Tamandaré.

Com relação à Formação Algodoais, aqui descrita com maior ênfase, Lima Filho (1998) classificou esta formação como sedimentos vulcanocláticos retrabalhados, principalmente, na sua unidade inferior e média. As rochas vulcanoclásticas estão presentes apenas nas porções mais proximais da Bacia Pernambuco. Atentamos a presença das fácies sedimentar vulcanogênica, exemplificada na figura 10A e, da evidência de grãos de quartzos com embainhamento (Fig. 10B, 12A e B), para a região centro-sul da Bacia Pernambuco. De acordo com Lima Filho (1998), a Formação Algodoais envolve todos os materiais vulcânicos que tenham sido afetados por agentes de erosão e transporte.

\section{Conclusões}

A análise combinada de feições geomorfológicas, através do uso do MDE-TIN, de estruturas magnéticas e dados de campo compreendeu uma metodologia integrada útil para a construção do mapa geológico-estrutural em escala 1:25.000 de parte do setor centro-sul da Bacia Pernambuco.

O MDE-TIN proporcionou a interpretação das relações geomorfológicas e topográficas, como a ocorrência de determinadas unidades litoestratigráficas (e.g. embasamento, rochas vulcânicas e sedimentares). Possibilitou também a análise de lineamentos estruturais que, assim como demonstrado nas imagens magnetométricas, apresentam trends preferenciais NE-SW, correspondendo a falhamentos normais, enquanto os trends NNWESE e NW-SE estão relacionados aos falhamentos de transferência/transcorrência.

Seis unidades litoestratigráficas foram reconhecidas, abrangendo o embasamento cristalino, a Formação Cabo, a Suíte Magmática Ipojuca, as formações Estiva e Algodoais, e depósitos quaternários (aluviões, mangues ou depósitos flúvio-lagunares, beachrocks e/ou recife de corais, e depósitos litorâneos praiais). Fácies vulcanogênica estão associadas com a Formação Algodoais.

A ação de processos intempéricos intensos e erosivos, além de ampla cobertura de depósitos quaternários, são os principais fatores que dificultam uma melhor caracterização das unidades litoestratigráficas na região de estudo.

As estruturas magnéticas circulares, interpretadas em imagem da amplitude do sinal analítico, possivelmente, demostram centros vulcânicos rasos, sugerindo-se a assinatura de dois grandes centros vulcânicos, um na porção leste da área de estudo (CV1), e outro localizado na porção centro-sudoeste (CV2). O CV1 se propaga em direção ao platô de Pernambuco, enquanto o CV2 mostra certa associação com os dados de campo, caso dos altos gradientes magnéticos locais associados com basaltos e riolitos da SMI, e a existência de ocorrência de fácies sedimentar vulcanogênica da Formação Algodoais na área de influência desse setor CV2.

\section{Referências}

Almeida, C.B. 2003. Mapeamento Geológico da região do Engenho Sibiró - Porto de Galinhas (litoral sul, PE): contribuição à estratigrafia e à tectônica da Sub-bacia de Pernambuco. Natal. 
87p. Relatório de Graduação, Departamento de Geologia, Universidade Federal de Rio Grande do Norte.

Arrais, M.S.M.C., Correia, P.B, Santos, E.J.S. \& Araujo, S.D.D. 2010. Estruturas magnéticas circulares na Bacia de Pernambuco: diques anelares ou edifícios vulcânicos? Estudos Geológicos, 20(1): 101-115.

Barbosa, J.A., Pereira, P.J.F. \& Lima Filho, M.F. 2008. Dente de um picnodontiforme (Actinopterygii, Neopterygii) da Formação Estiva, Cenomaniano-Turoniano da Bacia de Pernambuco, NE do Brasil. Journal of Geoscience, 4(2): 43-48.

Boggs Jr., S. 2009. Petrology of sedimentary rocks. 2nd edition, Cambridge, Cambridge university press, 600p.

Briggs, I.C. 1974. Machine contouring using minimum curvature. Geophysics, 39(1): 39-48.

Collinson, J.D. 1996. Alluvial sediments. In: Reading, H.G. (ed.) Sedimentary Environments: Processes, Facies and Stratigraphy: W.H. Freeman, p. 37-81.

Córdoba, V.C., Jardim De Sá, E.F., Sousa, D.C. \& Antunes, A.F. 2007. Bacia de PernambucoParaíba. Boletim de Geociências da Petrobras, 15(2): 391-403.

Correia Filho, O.J. 2017. Análise de estruturas compressionais na região onshore da Bacia Pernambuco, NE do Brasil - possíveis influências no potencial petrolífero. Recife. 160p. Dissertação de Mestrado, Programa de Pós-graduação em Geociências, Universidade Federal de Pernambuco.

Cruz, L.R., Lima Filho, M.F., Neumann, V.H.M.L., Jardim de Sá, E.F., Silva, F.C.A., Luiz Frutuoso Jr., L.J., Nascimento, M.A.L., Guedes, I.M.G., Antunes, A.F., Almeida, C.B. \& Melo, K.J.V. 2003. As unidades siliciclásticas da sub-bacia de Pernambuco: uma revisão lito-estratigráfica. In: CONGRESSO BRASILEIRO DE P\&D EM PETRÓLEO \& GÁS, 2., 2003, Rio de Janeiro.

Lima Filho, M.F. 1998. Análise estratigráfica e estrutural da Bacia Pernambuco. São Paulo. 139p. Tese de Doutorado, Programa de Pósgraduação em Geoquímica e Geotectônica, Instituto de Geociências, Universidade de São Paulo.

Lima Filho, M.F., Barbosa, J.A. \& Souza, E.M. 2006.
Eventos tectônicos e sedimentares nas bacias de Pernambuco e da Paraíba: implicações no quebramento do Gondwana e correlação com a Bacia do Rio Muni. Geociências, 25(1): 117126.

Magalhães, J.R., Barbosa, J.A., Oliveira, J.T.C. \& Lima Filho, M.F. 2014. Characterization of the ocean-continent transition in the Paraíba Basin and Natal Platform region, NE Brazil. Revista Brasileira de Geofísica, 32(3): 481-496. Maia, M.F.B. 2012. Revisão da estratigrafia do intervalo aptiano-albiano da Bacia de Pernambuco, Nordeste do Brasil. Recife. 226p. Dissertação de Mestrado, Programa de Pósgraduação em Geociências, Universidade Federal de Pernambuco.

Maia, M.F.B., Barbosa, J.A., Lima Filho, M.F., Mort, H.P. \& Santana, F.R. 2012. Características petrográficas e geoquímicas das formações siliciclásticas (Aptiano-Albiano) da Bacia de Pernambuco, NE do Brasil. Estudos Geológicos, 22(1): 55-75.

Müller, A., van den Kerkhof, A.M., Behr, H.-J., Kronz, A. \& Koch-Müller, M. 2009. The evolution of lateHercynian granites and rhyolites documented by quartz - a review. Earth and Environmental Science Transactions of the Royal Society of Edinburgh, 100: 185-204.

Nascimento, M.A.L. 2003. Geologia, Geocronologia, Geoquímica e petrogênese das rochas ígneas cretáceas da Província Magmática Cabo e suas relações com as unidades sedimentares da Bacia Pernambuco (NE do Brasil). Natal. 264p. Tese de Doutorado, Programa de Pós-graduação em Geodinâmica e Geofísica, Universidade Federal do Rio Grande do Norte.

Neves, S.P., Mariano, G., Beltrão, B.A. \& Correia, P.B. 2005. Emplacement and deformation of the Cachoeirinha pluton inferred through petrostructural studies: constraints on regional strain fields. Journal of South American Earth Sciences, 19: 127-141.

Osako, L.S. 2005. Caracterização geológica da região situada entre as localidades de Paranatama e Currais Novos (PE) porção centro-norte do domínio tectônico Pernambuco-Alagoas, Província Borborema. Recife. 165p. Tese de doutorado, Programa de 
Pós-graduação em Geociências, Universidade Federal de Pernambuco.

Passos, V.S.A. 2019. Mapeamento geológico da Bacia Pernambuco (Folha Sirinhaém-SC.25V-A-V-2-NE, SC.25-V-A-VI-1-NO/1:25.000): aspectos estratigráficos e magnetométricos, área 2. Recife. 89p. Relatório de Graduação, Departamento de Geologia, Universidade Federal de Pernambuco.

Peucker, T.K., Fowler, R.J., Little, J.J. \& Mark, D.M. 1978. The triangulated irregular network. Proceedings..., Digital Terrain Model Symposium, St. Louis, MO. 516-532.

Roest, W.R., Verhoef, J. \& Pilkington, M. 1992. Magnetic interpretation using $3-D$ analytic signal. Geophysics, 57: 116-125.

Santos, E.J., Correia, P.B., Silva, J.M.R., Arruda, S.D.D., Lima Filho, M.F., Barbosa, B.M.A. \& Botelho, E.S. 2011. Estudo geodinâmico e evolução estratigráfica (pré-rifte/ rifte) das bacias sedimentares Sergipe/ Alagoas, Recôncavo, Tucano Sul, Camalaú, Almada, Pelotas e Pernambuco e de seus embasamentos cristalinos. Relatório sobre a Bacia Pernambuco: interações embasamento-cobertura e tópicos sobre a evolução tectônica da Bacia Pernambuco e da área oceânica adjacente. Relatório técnico. Projeto Petrobras (Inédito).

Silva Filho, A.F., Guimaraes, I.P., Santos, L., Armstrong, R. \& Van Schmus, W.R. 2016. Geochemistry, U-Pb geochronology, Sm-Nd and $\mathrm{O}$ isotopes of ca. $50 \mathrm{Ma}$ long Ediacaran High-K Syn-Collisional Magmatism in the Pernambuco Alagoas Domain, Borborema Province, NE Brazil. Journal of South American Earth Sciences, 68: 134-154.

Silva Filho, A.F., Guimaraes, I.P. \& Van Schmus, W.R. 2002. Crustal Evolution of the PernambucoAlagoas Complex, Borborema Province, NE Brazil: Nd Isotopic Data from Neoproterozoic Granitoids. Gondwana Research, 5(2): 409422.
Silva Filho, A.F., Guimarães, I.P., Van Schmus, W.R., Armstrong, R.A., Rangel da Silva, J.M., Osako, L.S. \& Cocentino, L.M. 2014. SHRIMP U-Pb zircon geochronology and $\mathrm{Nd}$ signatures of supracrustal sequences and orthogneisses constrain the Neoproterozoic evolution of the Pernambuco Alagoas domain, southern part of Borborema Province, NE Brazil. International Journal of Earth Sciences, 103: 2155-2190.

SUDENE. Superintendência do Departamento do Nordeste. 1974. Carta Topográfica do Município de Sirinhaém. Ministério do Interior. Superintendência do Desenvolvimento do Nordeste. Folhas SC.25-V-A-2-NE, SC.25-VA-VI-1-NO, Região Nordeste do Brasil, 1 mapa $(1: 25.000)$.

Van Schmus, W.R., Kozuch, M. \& Brito Neves, B.B. 2011. Precambrian History of the Zona Transversal of the Borborema Province. Journal of South America Earth Sciences 31: 227-252. 